\title{
Presentación \\ El desarrollo de la familia en España desde una perspectiva demográfica
}

Nos complace presentar un número monográfico de PAPERS. REVISTA DE Sociologia sobre demografía y familia en España. Creemos que, en este mosaico de nueve artículos, se encontrará una panorámica muy completa de todos los temas que tratan del desarrollo familiar contemporáneo en España desde una perspectiva demográfica. Los primeros trabajos están relacionados con la formación de la pareja y su disolución, para entrar a continuación en el tema del desarrollo de la familia a través de la fecundidad y acabar con cuatro puntos que nos parecen fundamentales en relación con el desarrollo familiar, a saber: el mercado inmobiliario, el envejecimiento, la movilidad residencial de retorno y la nueva inmigración internacional.

Se inicia este recorrido con el análisis de una dimensión de la emancipación juvenil, la que elige como vehículo en la transición al mundo adulto el matrimonio o la unión consensual. Es la «Emancipación juvenil a través de la formación de la pareja», un artículo firmado por Pau Miret. De hecho, se contraponen dos situaciones entre la población joven en España: el convivir sin pareja con los padres o hacerlo con la pareja pero sin los padres. Así, se estima qué factores están relacionados con el hecho de vivir en pareja en vez de seguir en el domicilio parental. Es cierto que ello no agota el estudio de la emancipación residencial, pues esta transición puede tener lugar a través de la formación de un hogar no familiar (unipersonal o con un grupo de amigos, por ejemplo), pero a finales del siglo XX, en España, ésta continuaba siendo una vía inmensamente mayoritaria. Se compara el modelo de 1991 con el de 2001, utilizando en ambos momentos la información censal. Ante todo, se controla la influencia de la edad, pues es ley de vida que, a mayor edad, menor probabilidad de seguir con los padres $y$, complementariamente, mayor probabilidad de haber formado un hogar independiente a través de la pareja. A continuación, se presenta la relación con la actividad y el nivel de instrucción y su influencia en la emancipación juvenil a través de la pareja según género.

Faltaba poco para la legalización del matrimonio homosexual en España cuando tuvo lugar el trabajo de campo del censo de 2001, la primera operación de este tipo que "permitió» a las parejas del mismo sexo definirse como tales. 
Clara Cortina y Anna Cabré inauguran el análisis demográfico sobre este tema con el artículo "Las uniones homosexuales en España», pues — como ellas mismas afirman - se ha dado una ausencia de investigación empírica sobre este tipo de uniones. A través de la corresidencia y la autodefinición en el censo de 2001 de una pareja como "de hecho" (hasta 2005 no existiría la posibilidad de serlo "de derecho»), las autoras se plantean una descripción de las características sociodemográficas de los miembros de las uniones homosexuales y su distribución territorial en España: ¿`se concentran en alguna región en especial?, ¿son más jóvenes?, ¿se dan más entre hombres que entre mujeres? Y si es así, a qué se pueden achacar estas diferencias. Ésta y otras preguntas (como también sobre la estructura educativa o la nacionalidad) tienen cumplida respuesta en el segundo artículo. Unas variables de las que se presenta su efecto tras limpiarlo de posibles interferencias con otras variables, tanto a nivel individual como en relación con el grado de homogamia de las parejas. Como se descubrirá con su lectura, la cantidad y la calidad de información dispuesta por este trabajo lo señala como un artículo de referencia, tanto por su novedad como por su precisión científica.

Son necesarias dos personas para formar una pareja. Esta perogrullada viene a cuento a raíz del siguiente trabajo, el de Albert Esteve y Clara Cortina sobre la "Expansión educativa e inmigración internacional en España: cambios en la formación de la pareja». No son tan comunes los estudios de este fenómeno que incluyan la relación entre los miembros de la pareja o, utilizando el concepto apropiado, analicen la homogamia en el núcleo conyugal, pues habitualmente se estudia la constitución de la unión según sexo, de manera independiente para hombres y mujeres. El artículo que contiene este monográfico rompe con esta tendencia. El nivel de instrucción es la variable clave del análisis y vemos a través de ella de qué manera las uniones se contraen entre personas cada vez más diferentes en este aspecto, con una remarcable excepción: los cónyuges con estudios superiores cada vez se unen más dentro de su grupo educativo. Finalmente, se nos presenta que la nueva inmigración sigue pautas idiosincrásicas muy distantes a las dibujadas por la población española, aunque ello dependa mucho de la nacionalidad (así, por poner algunos ejemplos, las constituidas por europeos tienden a ser más homogámicas y aquéllas entre africanos o latinoamericanos suelen ser más desequilibradas en la relación de género). De todo ello y mucho más trata este artículo, con el que cerramos el tema de la formación de la pareja.

La convivencia en pareja es una situación reversible, aunque no necesariamente. Ello hace imprescindible, en el análisis de la dinámica familiar, el estudio de la dinámica de la separación: de ahí la pertinencia del artículo de Carles Simó y Montse Solsona sobre «El registro estadístico de las rupturas de unión en España», que busca localizar y describir pormenorizadamente las fuentes de información sobre un fenómeno que cada vez cobra mayor importancia, por lo que cada vez se acusa más la falta de estudios sobre el tema. El artículo quiere iluminar sobre el particular con — como reza el subtítulo del mismouna «evaluación e ideas para avanzar desde la demografía», un profundo aná- 
lisis al que ya nos tienen acostumbrados sus autores. El objetivo deviene especialmente complejo por la tremenda dispersión de la información (cuando la hay), hecho que queda de manifiesto en el trabajo, que ahorrará mucho tiempo a quienes deseen analizar la ruptura de la unión, pues no tendrán que rebuscar en las estadísticas, sino ir directamente a consultar las fuentes indicadas. La investigación se inicia con una clara presentación de la historia legislativa del divorcio y de los datos estadísticos que en España se derivan de este acto jurídico, encuadrado en las recomendaciones que se dan desde organismos internacionales, que también se exponen en el texto. A continuación, se compara lo que se posee con lo que se precisaría para un correcto análisis del fenómeno, con todo un listado de los problemas que surgen entre el deseo de saber y el poder de conocer. A través del artículo, además, se presenta la historia de las luces y sombras en el análisis de la formación y la disolución de las uniones o de la situación de convivencia en pareja en un momento determinado en el tiempo, comparándolo con la experiencia en otros países europeos.

El análisis de la dinámica familiar llega a su máximo exponente demográfico con el análisis de la fecundidad, con una perspectiva histórica y territorial, y desde el estudio de la misma según orden de nacimiento, unos aspectos de los que normalmente carecemos en el análisis sobre el tema. Así, presenciamos, a través del estudio, la evolución de la fecundidad en España, con una convergencia de pautas a escala provincial en las probabilidades de tener menos de dos hijos, aunque no en las de tener dos y más. El porqué de esta realidad se explica detalladamente a lo largo del estudio de Roser Nicolau, Daniel Devolder y Eva Panareda, «La modernización de los comportamientos de fecundidad en España durante el siglo XX». Para ello, se aprovechan los datos que, a partir del censo de 1920, se recogen sobre los hijos nacidos vivos de manera retrospectiva y que se repitió en censos posteriores. En concreto, los autores utilizan los censos de 1970 y de 1991. Para empezar, se analiza la infecundidad, o porcentaje de mujeres sin hijos, para mostrar cómo se ha ido reduciendo fruto del incremento de la nupcialidad entre las mujeres y de la longevidad entre la población española. A continuación, se presenta el modelo del hijo único y el de tener más de un hijo. A partir de aquí, el trabajo deriva a cómo inferir de los datos estadísticos utilizados si se ha dado o no un control de la fecundidad a lo largo y ancho del territorio español, para inferir hasta qué punto han tenido lugar procesos de difusión en España y en qué sentido. La respuesta a todo ello la tienen ustedes en este artículo. ¡No lo vamos a desvelar todo en la presentación!

El análisis del mercado de la vivienda nos ha parecido un tema consustancial para el análisis de la constitución y el desarrollo de la familia, por ello se encargó a dos especialistas del tema, Juan Antonio Módenes y Julián López, que nos iluminaran al respecto, de ahí el subtítulo de su artículo: «El sistema residencial español a la luz del censo de 2001", bajo el título más genérico de «Población y vivienda en España». Los autores desplazan el foco de la familia al hogar, es decir, al espacio de convivencia, no en vano ambos son geógrafos. De ello surgen preguntas que inciden directamente sobre el tema de este mono- 
gráfico, entre otras, encontramos: ¿Cuál es el régimen de tenencia según el tipo de hogar formado? ¿Qué características físicas tiene el edificio donde se ubica cada tipo de hogar? ¿Qué diferencias se establecen en función de la edad de la persona principal del hogar? Quien lea el artículo irá descubriendo progresivamente las peculiaridades del sistema residencial español o, en palabras de los autores, sus «ejes de diversidad».

Hay otro tema que no podía faltar en un análisis de la familia en España en la actualidad, a saber: la influencia del envejecimiento en el entorno familiar. Ainhoa Alustiza y Julio Pérez atacan con maestría este particular en el artículo «Familia, envejecimiento y discapacidad en España». La longevidad de la población española ha venido acompañada de una considerable mejoría en la calidad de vida en la vejez, tal y como muestran los autores, mal que los años — evidentemente - pesen a todo el mundo, aunque ser joven no es garantía de ausencia de discapacidad, pues, a la falta de años, se le une habitualmente cierto amor por el riesgo. De hecho, la edad es la primera variable en que se incide en este trabajo, para mostrar en qué momento biográfico se inicia una discapacidad. A continuación, se clasifica esta situación y se profundiza en las causas de la discapacidad. Una vez clarificado el terreno, se entra de lleno en el objeto de estudio de este monográfico, la familia, el hogar y las formas de convivencia en que se inscribe la población de referencia, para llegar a continuación a las características de quien cuida y quien precisa de cuidados, pues ya no es una persona completamente autónoma.

Finalmente, el tema con el que cerramos este número de PAPERS es el de la movilidad y las migraciones, y a ello se deben los dos últimos artículos del monográfico. El primero, firmado por Joaquín Recaño, introduce la dimensión familiar en las migraciones de retorno en España. El autor realiza un completo recorrido teórico por los textos que han considerado la familia como una variable intermedia entre el individuo y el contexto de la migración, en especial en los focalizados en la realidad española. Tras esta excelente introducción, la parte empírica del trabajo evalúa la inmigración de retorno en España, así como su situación familiar y de hogar que crean a su regreso. Su título resume todo su potencial innovador: "Las migraciones internas de retorno en España. De la óptica individual a la dimensión familiar».

Concluimos el recorrido del monográfico con un digno colofón dedicado a las migraciones internacionales, bajo el título «Los hogares de la población de nacionalidad extranjera en España, 2001», escrito por Andreu Domingo y Jordi Bayona. Este trabajo estudia las estrategias de la nueva inmigración, infiriéndolas del tipo de hogar formado y distinguiendo la nacionalidad de la persona de referencia. Para ello se basa en una tipología de los hogares utilizada por el Instituto Nacional de Estadística, pero con el objetivo manifiesto de ir mucho más allá de la mera clasificación. De esta manera, se verifica la mayor complejidad de los hogares de extranjeros respecto a los de españoles, lo que supone una mayor complejidad de sus estrategias familiares y dinámicas residenciales, que a su vez remite a diferentes etapas en el proceso migratorio. También se constatan claras diferencias según la nacionalidad de que se trate. 
Además, los autores se embarcan en dibujar las características de las viviendas de la población extranjera según su nacionalidad, analizando, por ejemplo, la densidad en la vivienda o la relación de actividad de los miembros del hogar.

Con este número especial sobre el desarrollo de la familia en España desde una perspectiva demográfica, nos habíamos propuesto tocar gran parte de las teclas requeridas para un análisis lo más exhaustivo posible sobre esta extensa área de investigación. Esperamos haberlo conseguido. En sus manos está juzgar si así ha sido. 